\title{
La impronta de las sentencias Francovich, Bosman, Kadi y Factortame en la jurisprudencia de la Unión Europea (1988-2013)
}

\author{
David Ordóñez Solís \\ Magistrado, Doctor en Derecho y miembro de la Red de Expertos en Derecho \\ de la Unión Europea del Consejo General del Poder Judicial
}

\begin{abstract}
Sumario: I. Introducción. - II. La sentencia Francovich (1991): la responsabilidad de las autoridades nacionales y la indemnización en caso de violación del Derecho comunitario europeo. - III. La sentencia Bosman (1995): nada que tenga dimensión económica, ni siquiera el deporte, es ajeno al Derecho de la Unión.-IV. La sentencia Kadi (2008): el alcance de la protección de los derechos fundamentales en la Unión Europea. - V. El asunto Factortame y el Derecho comunitario europeo en acción. - VI. Conclusión. - VII. Jurisprudencia citada.
\end{abstract}

\section{Introducción}

En 1988, cuando nace Cuadernos Europeos de Deusto, Europa está gestando un cambio que se escenificará al año siguiente con la caída del Muro de Berlín. Las Comunidades Europeas acaban de acoger en 1986 a dos países como España y Portugal y han intentado responder al reto que supone que la familia de la Europa de los Seis se haya duplicado. Las reivindicaciones desde legitimidad democrática del Parlamento Europeo elegido por sufragio universal en 1979 pretenden transformar unos procedimientos institucionales muy limitados y procuran ampliar sus competencias para tener no solo una voz económica sino también una voz en la política exterior. El Acta Única acababa de entrar en vigor en 1987 y Jacques Delors impulsaba el perfeccionamiento del mercado único.

Por tanto, el viejo orden tendrá que ser renovado y eso en el lenguaje europeo se llamará Maastricht y en esa ciudad holandesa se firmará en 1992 el Tratado de la Unión Europea. Al poco se abrirá la Unión de modo natural en 1994 a tres Estados de la Asociación Europea de Libre Comercio y no mucho después, coincidiendo con la adopción del euro en 1999, se producirá la gran apertura hacia los Países de Europa Central y Oriental. De 6 Estados fundadores hemos pasado a 28 miembros actuales y de 4 lenguas oficiales a la 24 de hoy en día. 
La elección de las sentencias que han dejado huella es una mera licencia de cada comentarista que necesariamente tiene una posición muy precisa en el tiempo, en un país y que está condicionado por su propio perfil profesional. Además si la elección de los hitos de la jurisprudencia, por meras razones editoriales tiene que concentrarse en tres o cuatro decisiones lo que hace que la elección sea realmente complicada ${ }^{1}$.

La perspectiva temporal es esencial para la elección de las sentencias de modo que cuanto más lejano en el tiempo sea el período estudiado más fácil es la selección. Así, por ejemplo, si hubiese que elegir tres o cuatro sentencias hasta 1988 sería fácil coincidir en que las sentencias Van Gend en Loos, Costa / ENEL, Simmenthal y un caso muy significativo como el de la Sra. Defrenne podrían ser representativos de esta época fundacional.

Parece que no hay que justificar la fundación del efecto directo y de la primacía con Van Gend en Loos y Costa / ENEL, y la argumentación que se funda en un nuevo orden jurídico. Ya resulta más complicado decantarse por Simmenthal pero no hay duda de que en los años 70 la intervención de los Tribunales Constitucionales alemán e italiano reclamaba una reafirmación del propio Tribunal de Justicia sobre la autonomía del Derecho comunitario europeo. En fin, la saga Defrenne, que se observa en las tres sentencias del Tribunal de Justicia respondiendo a los jueces belgas, puede considerarse un verdadero símbolo y un ejemplo magnífico de la evolución de una integración inicialmente económica hacia una integración más sensible con los derechos fundamentales, en este caso con el principio de igualdad entre mujeres y hombres.

En cambio, ya es más difícil ponerse de acuerdo en los últimos 25 años $y$, por poner un ejemplo, es probablemente demasiado pronto para saber si la sentencia Pringle significarán algo en la historia constitucional eu-

${ }^{1}$ CHEVAlLIER, R-M., y BOULOUIS, J., Les grands arrêts de la Cour de justice des Communautés européennes. Tome 1, Caractères généraux du droit communautaire, droit institutionnel, contrôle juridictionnel, y Tome 2, Libre circulation des marchandises, des personnes, des services et des capitaux. Concurrence. Dispositions fiscales. Agriculture. Transports. Politiques économique, commerciale, sociale, Dalloz, París; la primera edición es de 1974 y ha tenido numerosas ediciones. KARPENSCHIF, M., y NOURISSAT, C., Les grands arrêts de la jurisprudence de l'Union européenne, PUF, París, 2010, hacen una selección de 100 sentencias. En español la obra más reconocida es la de ALONSO GARCÍA, R., Las sentencias básicas del Tribunal de Justicia de la Unión Europea, Thomson Civitas, Navarra, publicado por primera vez en 2006 y que en 2012 ya iba por la 4. ${ }^{a}$ edición, donde selecciona 45 sentencias. En una perspectiva histórica véanse los hitos a los que se refiere TAMM, D., «The History of the Court of Justice of the European Union Since its Origin», en The Court of Justice and the Construction of Europe: Analyses and Perspectives on Sixty Years of Caselaw - La Cour de Justice et la Construction de l'Europe: Analyses et Perspectives de Soixante Ans de Jurisprudence, Asser Press, La Haya, 2013, pp. 9-35. 
ropea dentro de otros 25 años a pesar de que hace poco menos de un año, cuando más arreciaba la crisis del euro, el Tribunal de Justicia logró calmar las turbulencias constitucionales planteadas desde el Tribunal Supremo irlandés.

Los criterios cuantitativos no dejan de ser indicativos de modo que basta con examinar los índices de las Revistas o, en particular, revisar los propios Cuadernos Europeos de Deusto para comprobar cuáles han sido las preocupaciones europeas en los últimos 25 años. No obstante, la necesaria especialización puede distorsionar la elección. Así, cuanto más se profundiza en un determinado sector del ordenamiento más en falta se echarán sentencias básicas de modo que, por poner solo algunos ejemplos, en el ámbito de las libertades económicas, la fiscalidad, la contratación pública o el espacio de libertad, seguridad y justicia, la elección tendría, desde luego, que haber barajado sentencias esenciales. De modo que no se entienden las referidas regulaciones sectoriales sin mencionar sentencias de estos últimos 25 años como Keck, Schumacker, Ordine degli Architetti, o Pupino, respectivamente.

También la perspectiva geográfica es importante porque no ha tenido la misma repercusión en la Unión Europea que, por ejemplo y muy recientemente, en España la sentencia Aziz, que, después de un amplio impacto mediático, ha obligado a modificar una legislación centenaria sobre ejecución hipotecaria; o incluso la sentencia Melloni, donde por vez primera el Tribunal Constitucional español ha superado su miedo al reenvío prejudicial a Luxemburgo cuando, sin embargo, ya lo habían hecho homólogos europeos de Bélgica, Italia, Austria y, después del español, de Francia.

En fin, la profesión del comentarista es relevante por su mayor o menor dimensión académica, generalmente preocupada por un área muy precisa del Derecho público o privado, o por su particular experiencia judicial, más abierta, por lo general, a los aspectos prácticos e interdisciplinares. $\mathrm{O}$ incluso su propia experiencia y su conocimiento de las entrañas del caso desde la perspectiva nacional como ocurre respecto de este comentarista con Marleasing.

En todo caso, los criterios que se pueden tener en cuenta para la elección pueden estar justificados si, por ejemplo, comprobamos que la actividad más relevante del Tribunal de Justicia es la de responder cuestiones prejudiciales; si, además, las materias afectadas tienen carácter transversal de modo que, una vez resuelto el problema del efecto directo y de la primacía, la cuestión clave pendiente será la de la responsabilidad. En fin, convendría elegir cuestiones prejudiciales, pero también recursos como el de anulación, como garantía frente a las instituciones de la Unión, o el mismo recurso de incumplimiento tan íntimamente relacionado con el reenvío prejudicial. 
Por eso y en primer lugar la sentencia Francovich, resultado de una cuestión prejudicial procedente de Italia, puede considerarse como la continuación natural y el corolario de la saga fundacional Van Gend en Loos, Costa / ENEL y Simmenthal.

En segundo lugar y aun cuando toda elección resulta injusta con los pasos previos y con los desarrollos posteriores que en realidad hacen grande una sentencia, no puede negarse la repercusión mediática. Tal es el caso de la sentencia Bosman, resultado de una cuestión prejudicial belga y conocida en algún momento con el apelativo mediático de «ley Bosman», y que ha sido relevante en el deporte pero que también constituye una audaz interpretación jurisprudencial que se había gestado veinte años al aplicar las libertades económicas a los deportistas profesionales.

Los derechos fundamentales y su protección en la Unión Europea son esenciales en la comprensión del Derecho contemporáneo y la solución que ha venido elaborando con paciencia el Tribunal de Justicia y las adaptaciones constitucionales, en particular, la adopción de la Carta de Derechos Fundamentales de la Unión justificarían la elección de una sentencia particularmente polémica pero también valiente como la sentencia Kadi, dictada en un recurso de anulación donde el Tribunal de Justicia enmienda la posición del Tribunal de Primera Instancia, relativiza el marchamo de las Naciones Unidas y obliga a ser más escrupuloso con la protección de los derechos fundamentales de todas las personas.

En fin, si por seguir con el paralelismo de las cuatro primeras décadas de jurisprudencia europea en las que se habría considerado relevante la jurisprudencia Defrenne, lo mismo podría decirse del asunto Factortame donde los tribunales de Londres recurrieron sucesivamente al Tribunal de Justicia planteándole cuestiones esenciales de la integración europea y sobre sus efectos en los ordenamientos nacionales, desde una perspectiva tan particular en todos los sentidos como es el Derecho británico. Pero este caso permite observar que a la solución del litigio contribuye de manera decisiva la intervención de la Comisión Europea que por su cuenta acude al Tribunal de Justicia interponiendo un recurso por incumplimiento contra el Reino Unido. Los armadores afectados, la gran mayoría de nacionalidad española, reclaman también la indemnización de los perjuicios sufridos por incumplimiento del Derecho comunitario europeo por parte del Parlamento británico.

Las anteriores razones son las que, de una manera personal y sometido a un límite cuantitativo razonable, me permiten considerar que en los últimos 25 años las sentencias Francovich, Bosman, Kadi y probablemente el caso Factortame explicarían incluso dentro de muchos años este periodo de la integración europea, por lo demás apasionante y al que Cuadernos de Estudios Europeos ha tratado de aportar luz. 


\section{La sentencia Francovich (1991): la responsabilidad de las autoridades nacionales y la indemnización en caso de violación del Derecho comunitario europeo}

A principios de 1990 llegan a Luxemburgo dos cuestiones prejudiciales planteadas por sendos Juzgados italianos cercanos a Venecia en dos asuntos muy similares. Dos empresas habían sido condenadas al pago de indemnizaciones a sus trabajadores pero en un caso los embargos habían resultado fallidos y en el otro la empresa había quebrado. Al no poder cobrar de sus empresas los trabajadores interpusieron sendos recursos frente al Estado italiano y recurrieron a los jueces de Vicenza y de Bassano del Grappa invocando la vigencia de la Directiva 80/987/CEE de protección de los trabajadores asalariados en caso de insolvencia del empresario que no había sido incorporada al Derecho italiano a pesar de que se había fijado 1983 como el plazo máximo de transposición.

Los dos tribunales italianos de instancia acuden al Tribunal de Justicia con tres preguntas idénticas que las reformula y articula su respuesta pronunciándose sobre dos aspectos: por una parte, sobre el efecto directo de las disposiciones de la Directiva que definen los derechos de los trabajadores y, por otro lado, en relación con la existencia y el alcance de la responsabilidad del Estado por los daños resultantes del incumplimiento de las obligaciones que le incumben en virtud del Derecho comunitario.

El abogado general Jean Mischo había advertido en su Conclusiones, presentadas el 28 de mayo de 1991, sobre la trascendencia de este asunto y desarrolla de modo pormenorizado la jurisprudencia que luego, más sucintamente, va a utilizar el Tribunal de Justicia.

En su primera respuesta el Tribunal de Justicia subraya la falta de efecto directo de la Directiva porque, pese a que sus disposiciones son precisas e incondicionales en lo que respecta al contenido de la garantía, no determinan quién es el obligado a prestarla. Y, por otra parte, el Estado no puede ser considerado como obligado solo por no haber adoptado en el plazo establecido las medidas de adaptación de su Derecho nacional a la Directiva. En consecuencia, la falta de efecto directo de la Directiva impide satisfacer por esa vía las demandas de los trabajadores.

Sin embargo, será la segunda respuesta la que busque una alternativa subsidiaria y fundada en el principio de la responsabilidad de los Estados miembros por violación del Derecho comunitario. La reformulación que hace el Tribunal de Justicia de la pregunta de los tribunales italianos es si un Estado miembro está obligado a reparar los daños que resulten para los particulares de la no adaptación del Derecho nacional a la Directiva 80/987 o ya en términos más generales: si existe y cuál es el alcance de una responsabilidad del Estado por los daños resultantes del incumpli- 
miento de las obligaciones que le incumben en virtud del Derecho comunitario.

Es decir, el Tribunal de Justicia va a consagrar el principio del derecho de indemnización de los particulares por daños que hayan sufrido como consecuencia de la violación del Derecho comunitario de las autoridades nacionales. Y también establecerá los requisitos para que se genere este derecho de indemnización.

A partir de este planteamiento, el Tribunal de Justicia subraya que va a responder a la luz del sistema general del Tratado y de sus principios fundamentales. Y, seguidamente, el punto de partida es la naturaleza del Derecho comunitario tal como se deduce de las sentencias Van Gend en Loos, Costa / ENEL, Simmenthal y Factortame I.

A continuación, el Tribunal de Justicia recuerda la función de los tribunales nacionales en el ordenamiento comunitario europeo que consiste en garantizar la plena eficacia de tales normas y proteger los derechos que confieren a los particulares (apartado 32).

Y, por último, el Tribunal de Justicia llega a la conclusión de su razonamiento: «la plena eficacia de las normas comunitarias se vería cuestionada y la protección de los derechos que reconocen se debilitaría si los particulares no tuvieran la posibilidad de obtener una reparación cuando sus derechos son lesionados por una violación del Derecho comunitario imputable a un Estado miembro» (apartado 33).

Esto le permite al Tribunal de Justicia subrayar que «el principio de la responsabilidad del Estado por daños causados a los particulares por violaciones del Derecho comunitario que le son imputables es inherente al sistema del Tratado» (apartado 35). Y a continuación, basándose en una sentencia prácticamente desconocida hasta entonces, la sentencia Humblet, invoca el principio de cooperación leal aplicable a las autoridades nacionales de tal modo que «el Derecho comunitario impone el principio de que los Estados miembros están obligados a reparar los daños causados a los particulares por las violaciones del Derecho comunitario que les sean imputables» (apartado 37).

Y, por otra parte, desgrana los requisitos o los presupuestos que deben darse para que generar la responsabilidad del Estado. Se trata de tres requisitos que enuncia el Tribunal de Justicia pensando única y exclusivamente en el caso que está enjuiciando, es decir, el caso de la violación de una directiva: que el resultado prescrito por la Directiva implique la atribución de derechos a favor de particulares; que el contenido de estos derechos pueda ser identificado basándose en las disposiciones de la Directiva; y que exista una relación de causalidad entre el incumplimiento de la obligación que incumbe al Estado y el daño sufrido por las personas afectadas (apartado 40). 
Estos tres requisitos fueron, cinco años después, mejor aquilatados por otras sentencias, en particular por la sentencia Brasserie du pêcheur y Factortame. No obstante, ya en el asunto Francovich el Abogado General Mischo insiste de una manera más clara y directa en la relación que tiene el recurso por incumplimiento y la sentencia del Tribunal de Justicia que previamente había declarado el incumplimiento por Italia de la Directiva controvertida que el propio Tribunal de Justicia.

Por último, también el Tribunal de Justicia recuerda que para la reclamación de la reparación ante los tribunales nacionales se aplica el principio de autonomía institucional y procedimental que solo quedaría limitado por el principio de efectividad y de equivalencia. No obstante, también este punto será desarrollado ampliamente en la jurisprudencia posterior.

Leyendo ahora la sentencia Francovich puede observarse una cierta tosquedad o incluso confusión que solo la decantación de los casos posteriores ha permitido limitar. Sin embargo, el hallazgo jurisprudencial está en su primigenia manifestación: los trabajadores se han quedado sin cobrar de las empresas, el Estado italiano nada ha hecho por transponer una Directiva clara e incondicional, es más, ha hecho caso omiso de una sentencia del propio Tribunal de Justicia que declara el incumplimiento de la República italiana. En consecuencia, parece que corresponde a las autoridades italianas responder por haber violado el Derecho comunitario, por haber desconocido unos derechos reconocidos por el ordenamiento jurídico y por el hecho de que tal violación genera unos evidentes daños en los trabajadores demandantes de amparo ante los tribunales italianos.

Las consecuencias de esta sentencia han sido transformadoras para el Derecho de la Unión Europea. De hecho y con posterioridad, se ha producido una línea jurisprudencial empeñada en aclarar los conceptos sentados por la sentencia Francovich en cuanto se refiere a los distintos tipos de normas del Derecho comunitario violadas o el tipo de violación requerida según la autoridad nacional afectada, el legislador, la administración o el juez.

En el caso de las directivas pronto se desarrolló una jurisprudencia que precisó dos tipos de supuestos: aquellos en que las directivas habían sido incorrectamente transpuestas, que salvo en circunstancias particulares no generaban el derecho de indemnización, y aquellos en que no había habido ningún tipo de transposición. A juicio del Tribunal de Justicia la falta de incorporación suponía por sí sola una violación suficientemente caracterizada (sentencia Dillenkofer).

Cuando se examina si concurre la violación de un órgano del Estado, el Tribunal de Justicia ha distinguido, por ejemplo, el examen de la violación por el legislador (sentencia Brasserie du pêcheur y Factortame) o por los jueces en cuyo caso la exigencia para generar el derecho de indemnización 
se limita aún más a una violación «manifiesta» (sentencias Köbler y sentencia Traghetti del Mediterraneo).

En fin, la precisión del alcance de los principios de efectividad y equivalencia ha tenido importantes repercusiones en el Derecho español como lo ilustra, por todas, la sentencia Transportes Urbanos y Servicios Generales.

Por tanto, la sentencia Francovich ocupa el lugar más destacado de estos últimos 25 años de jurisprudencia del Tribunal de Justicia y su éxito reside en la aplicación, ciertamente ingeniosa aunque restrictiva, de los viejos principios del Derecho romano e incluso del Derecho internacional, el de la responsabilidad, traducido, eso sí, a un efectivo derecho de los particulares a la indemnización. De este modo se cierra el círculo abierto para el efecto directo en Van Gend \& Loos, para la primacía en Costa / ENEL y ahora para el derecho de indemnización en Francovich. Ciertamente, el ciudadano está en el punto de vista del Tribunal de Justicia.

\section{La sentencia Bosman (1995): nada que tenga dimensión económica, ni siquiera el deporte, es ajeno al Derecho de la Unión}

En Europa el deporte en general y el fútbol en particular son esenciales en nuestra sociedad. El caso Bosman es de los pocos asuntos judiciales que no son penales y que se hizo popular en Europa porque afectaba a reglas especialmente arraigadas en nuestra sociedad en virtud de las cuales era natural la discriminación por razón de la nacionalidad a la hora de alinear a los jugadores de una competición deportiva profesional, en este caso de los equipos de fútbol.

El futbolista belga Jean-Marc Bosman se enfrentó ante los tribunales belgas a su antiguo club, el Lieja, y a la UEFA por no permitirle jugar en el club francés de Dunquerque debido a las reglas relativas a la nacionalidad y a la reglamentación deportiva que exigía una compensación por transferencia, formación o promoción a favor del club de origen de jugador profesional.

Es justo recordar que 20 años antes el Tribunal de Justicia ya había tenido ocasión de decir en dos sentencias, una referida a los ciclistas tras moto Walrave y Koch y la otra relativa al futbolista italiano Donà, que la práctica de los deportes queda sometida al Derecho comunitario en cuanto constituya una actividad económica como es el caso de jugadores profesionales o semiprofesionales que ejercen una actividad retribuida.

La clave jurídica de la sentencia Bosman radica en la pregunta directa que hace el Tribunal de Apelación de Lieja sobre si se aplica la libre circulación de trabajadores, consagrada en el Tratado constitutivo, a unas regla- 
mentaciones adoptadas por Federación belga de fútbol, la UEFA o la FIFA, que afectan al ejercicio de una actividad por cuenta ajena por parte de deportistas profesionales en cuanto que los clubes de fútbol solo pueden alinear un número limitado de jugadores profesionales de otros Estados.

Para resolver el litigio planteado, el punto de partida del Tribunal de Justicia fue determinar, como había hecho con gran claridad y solvencia en sus conclusiones el Abogado General Carl Otto Lenz, si la regulación del Tratado constitutivo se aplicaba a los clubes y a las asociaciones deportivas.

El particular, el Tribunal de Justicia recuerda sus sentencias anteriores Walrave y Donà conforme a las cuales la práctica del deporte sólo está regulada por el Derecho comunitario en la medida en que constituye una «actividad económica» (apartado 73).

Al mismo tiempo, el Tribunal de Justicia precisó que, como ya había señalado en la sentencia Donà, «las disposiciones comunitarias en materia de libre circulación de personas y de servicios no se oponen a reglamentaciones o prácticas justificadas por motivos no económicos, relativos al carácter y al marco específicos de determinados encuentros»; pero también puntualizó que los aspectos deportivos no pueden ser invocados «para excluir toda una actividad deportiva del ámbito de aplicación del Tratado» (apartado 76).

El Tribunal de Justicia responde a las alegaciones de la UEFA y de los clubes deportivos en cuanto a las particularidades que ofrece el deporte y las consecuencias de aplicar la regulación económica europea al ámbito deportivo. Pero, de nuevo, el Tribunal de Justicia debe puntualizar que por muy importantes que puedan ser las eventuales consecuencias de la sentencia en la organización del fútbol en su conjunto, «no puede llegarse hasta el punto de distorsionar la objetividad del Derecho y poner en peligro su aplicación futura por causa de las repercusiones que puede tener una resolución judicial» (apartado 77).

Y tampoco acoge la aplicación de una especie de excepción deportiva a semejanza de la excepción cultural. Es más, el Tribunal de Justicia rechaza que quepa establecer una analogía entre el deporte y la cultura porque «la cuestión planteada por el órgano jurisdiccional nacional no se refiere a las condiciones de ejercicio de competencias comunitarias de amplitud limitada (como sería la cultura) sino al alcance de la libre circulación de trabajadores» (apartado 78).

Por esa razón, el Tribunal de Justicia establece el principio fundamental conforme al cual la libre circulación de trabajadores también se aplica a las reglamentaciones adoptadas por asociaciones deportivas internacionales como la UEFA o la FIFA referidas a las condiciones de ejercicio de una actividad por cuenta ajena por parte de deportistas profesionales (apartado 87). 
Esto significa herir de muerte a las reglas sobre alineación de un número limitado de jugadores en cada partido (apartado 137). Ciertamente, el Tribunal de Justicia no dejó de salvar los supuestos de las competiciones entre las selecciones nacionales de modo que la libre circulación de personas no se opone a normativas o prácticas que excluyan a los jugadores extranjeros de la participación en determinados encuentros por motivos no económicos relativos al carácter y al marco específicos de dichos encuentros y que, por lo tanto, se refieran únicamente al deporte como tal, como son los encuentros entre equipos nacionales de diferentes países (apartado 127).

La otra pregunta se refería a las normas sobre transferencias de los jugadores y el Tribunal de Justicia también declaró que era contraria a la libre circulación de trabajadores «la aplicación de normas adoptadas por asociaciones deportivas, con arreglo a las cuales un jugador profesional de fútbol nacional de un Estado miembro sólo puede, al término del contrato que le vincula a un club, ser empleado por un club de otro Estado miembro si este último ha abonado al club de origen una compensación por transferencia, formación o promoción» (apartado 114).

El Tribunal de Justicia admitió que estas reglamentaciones podían estar justificadas si perseguían un objetivo legítimo compatible con el Tratado, se fundaban en razones imperiosas de interés general y su aplicación era proporcionada (apartado 104). Sin embargo y en el caso concreto, las distintas justificaciones apuntadas por las federaciones deportivas no convencieron al Tribunal de Justicia de que la normativa entonces en vigor cumpliese las exigencias fijadas jurisprudencialmente (apartado 114).

Los efectos de la jurisprudencia Bosman fue extraordinaria dado que a partir de 1995 el Tribunal de Justicia tuvo que pronunciarse sobre los deportistas profesionales de otros países que integran el denominado Espacio Económico Europeo (es decir, Noruega, Islandia y Liechtenstein, más el caso particular y similar de Suiza) e incluso de terceros países que hubiesen adoptado un Acuerdo de asociación o cooperación con la Unión Europea como lo acredita un jugador eslovaco de balonmano contratado por un equipo de la segunda división alemana, Deutscher Handballbund; o dos conocidos futbolistas en la Liga española, uno ruso, Simutenkov, y otro turco, Nihat.

\section{La sentencia Kadi (2008): el alcance de la protección de los derechos fundamentales en la Unión Europea}

Los atentados en los Estados Unidos el 11 de septiembre de 2001 supusieron un abrupto inicio del siglo XXI y la lucha contra el terrorismo internacional ha puesto a prueba la solidez de nuestras sociedades en lo que se refiere precisamente a la defensa de los derechos fundamentales. La senten- 
cia Kadi puede representar precisamente el celo del Tribunal de Justicia por mantener estos valores sin perjuicio de la cooperación internacional.

El 15 de octubre de 1999 el Consejo de Seguridad aprobó la Resolución 1267 (1999) de lucha contra los talibanes y puso en marcha, a través de un Comité de Sanciones, un mecanismo de congelación de activos, de prohibición de viajar y de embargo de armas de aquellas personas o entidades asociadas a Al-Qaeda que fueron incluidas en una Lista que se ha ido actualizando hasta 2013. Precisamente en octubre de 2001 Yassin Abdullah Kadi y otras personas y entidades fueron asociados a Osama bin Laden y a la red terrorista Al-Qaeda por lo que la ONU los incluyó en la Lista.

Con el fin de cumplir esta obligación internacional la Unión Europea adoptó sucesivos reglamentos por los que imponía determinadas medidas restrictivas específicas contra determinadas personas y entidades asociadas al terrorismo. Tanto el Sr. Kadi como la entidad Al Barakaat interpusieron sendos recursos de anulación contra los Reglamentos n. ${ }^{\circ}$ 467/2001, n. $.^{\circ} 2062 / 2001$ y n. $.^{\circ} 2199 / 2001$ de los que conoció el Tribunal de Primera Instancia que, sin embargo, desestimó los recursos en virtud de sendas sentencias 2005 que fueron recurridas ante el Tribunal de Justicia.

Tanto en primera instancia como en casación la cuestión clave que debieron zanjar los tribunales comunitarios consistía en determinar si estos reglamentos respetaban los derechos fundamentales.

El Tribunal de Primera Instancia consideró que «las resoluciones del Consejo de Seguridad controvertidas no están sometidas en principio al control jurisdiccional del Tribunal de Primera Instancia y que éste no se encuentra autorizado a cuestionar, ni siquiera de modo incidental, la legalidad de las mismas desde el punto de vista del Derecho comunitario». No obstante, el Tribunal de Primera Instancia admite el control incidental de «la legalidad de las resoluciones del Consejo de Seguridad controvertidas desde el punto de vista del ius cogens, entendido como un orden público internacional que se impone a todos los sujetos del Derecho internacional, incluidos los órganos de la ONU, y que no tolera excepción alguna». Dentro de este parámetro excepcional de control incluye el Tribunal de Primera Instancia «el nivel de protección universal de los derechos fundamentales de la persona establecido en el ius cogens» (apartado 238) que, además, a su juicio, se vería garantizado por un órgano como el Comité de Sanciones que puede revisar en todo momento cualquier caso individual, mediante un mecanismo formalizado y que puede ser otra vía razonable para proteger adecuadamente los derechos fundamentales del demandante, tal como son reconocidos por el ius cogens (apartado 290).

En cambio, el abogado general Miguel Poiares Maduro en sus brillantes conclusiones propuso la anulación de los reglamentos. Para ello reformuló pedagógicamente la cuestión: «¿Atribuye el ordenamiento jurídico comu- 
nitario un estatus supra-constitucional a unas medidas que resultan necesarias para la aplicación de Resoluciones adoptadas por el Consejo de Seguridad?» (apartado 25).

El abogado general portugués se mostró convencido de la necesidad del control jurisdiccional y así lo subrayó: «La pretensión de que una medida es necesaria para el mantenimiento de la paz y la seguridad internacionales no puede surtir efectos hasta el punto de silenciar los principios generales del Derecho comunitario y de privar a los individuos de sus derechos fundamentales» (apartado 34).

El Tribunal de Justicia sigue esta misma orientación y anula los reglamentos por vulnerar, en primer lugar, el derecho de defensa en su dimensión de derecho a ser oído y el derecho a un control jurisdiccional al imponer a Kadi y a la fundación Al Barakaat la congelación de fondos (apartado 352).

En segundo lugar, el Tribunal de Justicia constató que había habido una violación del derecho de propiedad dado que los reglamentos, aun cuando podrían estar justificados, fueron adoptados «sin ofrecerle garantía alguna de que se le permitiría exponer su caso a las autoridades competentes, y ello en unas circunstancias en las que la restricción de su derecho de propiedad debe calificarse de considerable, habida cuenta del alcance general y de la duración efectiva de las medidas restrictivas que le fueron impuestas» (apartado 369).

Ahora bien, lo trascendental de la sentencia Kadi radica, como lo subrayó el abogado general Poiares Maduro, en la necesidad de imponer en todo caso un control de la garantía de los derechos fundamentales y las razones que justifican constitucionalmente este celo especial.

El punto de partida para el Tribunal de Justicia es que «la Comunidad Europea es una comunidad de Derecho, ya que ni sus Estados miembros ni sus instituciones pueden sustraerse al control de la conformidad de sus actos con la carta constitucional fundamental que constituye el Tratado y este último ha establecido un sistema completo de vías de recurso y de procedimientos destinado a encomendar al Tribunal de Justicia el control de legalidad de los actos de las instituciones» (apartado 281).

En segundo lugar, el Tribunal de Justicia recuerda su jurisprudencia sobre la protección de los derechos fundamentales y subraya: «los derechos fundamentales forman parte de los principios generales del Derecho cuyo respeto garantiza el Tribunal de Justicia. A este respecto, el Tribunal de Justicia se inspira en las tradiciones constitucionales comunes a los Estados miembros, así como en las indicaciones proporcionadas por los instrumentos internacionales relativos a la protección de los derechos humanos en los que los Estados miembros han cooperado o a los que se han adherido. El CEDH reviste en este contexto un significado particular» (apartado 283). 
En tercer lugar, el Tribunal de Justicia deduce que «el respeto de los derechos humanos constituye un requisito de legalidad de los actos comunitarios [y] no pueden admitirse en la Comunidad medidas incompatibles con el respeto de los derechos humanos» (apartado 284).

Por último, el Tribunal de Justicia se refiere al control de los actos de la Unión dictados en aplicación del Derecho internacional de modo que «el control de legalidad que debe así garantizar el juez comunitario recae en el acto comunitario destinado a aplicar el acuerdo internacional de que se trate, y no en este último como tal» (apartado 286).

En cambio, el Tribunal de Justicia rechaza tener competencia para controlar la legalidad de los actos internacionales, en este caso de las resoluciones del Consejo de Seguridad de las Naciones Unidas, ni siquiera limitando su control al examen de la compatibilidad de tal resolución con el ius cogens (apartado 287).

De este modo el Tribunal de Justicia parece salvar el espinoso problema de la primacía del Derecho internacional (apartado 288) pero, a continuación, desarrolla su doctrina conforme a la cual la primacía del Derecho internacional se aplicaría únicamente sobre los actos de Derecho comunitario derivado (apartado 307). Ahora bien, esta primacía del Derecho internacional respecto del Derecho comunitario «no se extendería al Derecho primario ni, en particular, a sus principios generales, entre los que figura el respeto de los derechos fundamentales» (apartado 308).

Y la razón de esta postura la expresa así el Tribunal de Justicia reafirmando que «el control de la validez de todo acto comunitario desde el punto de vista de los derechos fundamentales por parte del Tribunal de Justicia debe considerarse la expresión, en una comunidad de Derecho, de una garantía constitucional derivada del Tratado CE como sistema jurídico autónomo y que no puede ser menoscabada por un acuerdo internacional» (apartado 316).

Sin embargo, el Tribunal de Justicia, aun cuando se muestra receptivo hacia una cierta deferencia de las instituciones comunitarias con las instituciones de las Naciones Unidas, considera que esta deferencia debe basarse en una garantía judicial equivalente en el ámbito internacional controvertido.

Al examinar el sistema de garantías de los derechos respecto de las sanciones impuestas por el Comité de Sanciones, el Tribunal de Justicia comprueba que «el procedimiento ante dicho Comité sigue siendo esencialmente de naturaleza diplomática e interestatal, pues las personas o entidades afectadas no tienen una auténtica posibilidad de defender sus derechos y el Comité adopta sus decisiones por consenso, disponiendo todos sus miembros de un derecho de veto» (apartado 323).

Por tanto, la conclusión del Tribunal de Justicia es que «con arreglo a las competencias que les confiere el Tratado CE, los tribunales comunita- 
rios deben garantizar un control, en principio completo, de la legalidad de todos los actos comunitarios desde el punto de vista de los derechos fundamentales que forman parte integrante de los principios generales del Derecho comunitario, control que también se extiende a los actos comunitarios destinados a aplicar resoluciones aprobadas por el Consejo de Seguridad en virtud del capítulo VII de la Carta de las Naciones Unidas, como el Reglamento controvertido» (apartado 326).

La importancia de la sentencia Kadi estriba precisamente en la autoafirmación que hace el Tribunal de Justicia de su competencia, especialmente cuando están en juego derechos fundamentales, y supone un canto al control judicial que, prácticamente siguiendo el ejemplo del Tribunal Constitucional Federal alemán, advierte de que mientras que (solange, es la expresión en alemán) en el sistema de las Naciones Unidas no haya una garantía judicial apropiada de los derechos fundamentales el Tribunal de Justicia no cejará en su empeño.

\section{El asunto Factortame y el Derecho comunitario europeo en acción}

Hacia 1983 algunos armadores españoles constituyeron en el Reino Unido numerosas sociedades mercantiles con el fin de poseer y matricular buques de pesca hasta el punto de que en 1988 Factortame y otras sociedades controladas por españoles eran propietarias o explotaban 95 buques de pesca.

En 1988 se modificó la Ley británica relativa a la marina mercante para poner fin a la práctica consistente en el denominado «saqueo de las cuotas de pesca» atribuidas al Reino Unido por buques de pabellón británico pero que en realidad no estaban vinculados a los intereses británicos. La nueva legislación exigía para la inscripción en el nuevo registro de buques que el propietario fuese británico, que el buque fuese explotado o controlado desde el Reino Unido y que el armador fuese una persona o sociedad controlada por personas residentes o vinculadas al Reino Unido.

Con el fin de combatir esta legislación discriminatoria se pusieron en marcha distintas acciones ante los tribunales de Londres y varios recursos ante el Tribunal de Justicia que provocaron unas decisiones particularmente interesantes en el Derecho comunitario europeo.

En 1989 la Comisión Europea interpuso un recurso por incumplimiento contra el Reino Unido y al mismo tiempo solicitó del Tribunal de Justicia que suspendiese la aplicación de los nuevos requisitos de inscripción de buques vinculados a la nacionalidad. El Presidente del Tribunal de Justicia por auto de 10 de octubre de 1989 (246/89 R) acordó la suspensión.

También en 1989 Factortame y otras empresas presentaron un recurso contencioso-administrativo ante la High Court of Justice de Londres frente a la Ley de la marina mercante en cuanto se refería a los requisitos de inscrip- 
ción de buques y solicitaron la suspensión de su aplicación. El tribunal británico adoptó la medida cautelar que fue apelada por el Gobierno británico y la Court of Appeal anuló la medida cautelar. No obstante, esta decisión fue recurrida ante la Cámara de los Lores, que en ese momento y hasta 2009 era el Tribunal Supremo del Reino Unido, quien acudió al Tribunal de Justicia planteándole si tenía la facultad de suspender cautelarmente la aplicación de una ley nacional eventualmente contraria al Derecho comunitario.

La primera sentencia de 19 de junio de 1990, Factortame I (C-213/89) responde a la Cámara de los Lores en el sentido de que, efectivamente, cabe suspender una ley nacional si el juez nacional considera que podría ser contraria al Derecho comunitario.

La segunda sentencia del Tribunal de Justicia de 25 de julio de 1991, Factortame II (C-221/89), contesta la pregunta de la High Court of Justice de Londres y constata la disconformidad sustancial con el Derecho comunitario del régimen británico de la matriculación de los buques de pesca.

Prácticamente por las mismas razones el Tribunal de Justicia en virtud de la sentencia de 4 de octubre de 1991 (C-246/89) declara que el Reino Unido había incumplido las obligaciones que le imponía el derecho de establecimiento consagrado por el Tratado CEE.

Por último, el Tribunal de Justicia dicta una sentencia el 5 de marzo de 1996 en la que responde al mismo tiempo similares cuestiones planteadas en los asuntos Brasserie du Pêcheur (C-46/93) que proviene del Tribunal Supremo alemán, y Factortame, que plantea nuevamente desde Londres la High Court of Justice (C-48/93).

El Tribunal británico pretende saber en el asunto Factortame si procede una indemnización de los daños sufridos por los armadores españoles. La respuesta del Tribunal de Justicia es que los Estados miembros están obligados a reparar los daños causados a los particulares por las violaciones del Derecho comunitario que les sean imputables cuando el incumplimiento reprochado sea atribuido al legislador nacional (apartado 36), fija los requisitos precisos para que se genere tal derecho de indemnización y subraya, finalmente, que la reparación debe ser adecuada al perjuicio sufrido.

En el asunto Factortame las distintas vías judiciales nacionales y comunitarias están convenientemente coordinadas con el fin de permitir dar soluciones efectivas y satisfactorias a los legítimos intereses de los ciudadanos.

Por una parte, se plantea el problema de cómo resolver la contradicción entre una ley nacional y una norma del Derecho comunitario europeo. En este caso se ensayaron las dos vías, el recurso por incumplimiento y el reenvío prejudicial, llegando el Tribunal de Justicia a la misma constatación: la ley británica era contraria al derecho de establecimiento.

Adicionalmente, se planteó tanto en el recurso por incumplimiento como en el reenvío prejudicial el alcance de la adopción de medidas caute- 
lares con una solución también uniforme. El Tribunal de Justicia suspendió provisionalmente la aplicación la ley británica y, desde Luxemburgo, le dijo al juez británico que también tenía la facultad, si concurren los presupuestos tradicionales, de suspender una ley aprobada por su parlamento.

La potestad del juez nacional en la adopción de medidas cautelares está reforzada por el propio Derecho comunitario que se aplica y, por tanto, la solución provisional que adopta el Presidente del Tribunal de Justicia y los criterios que debe seguir el juez nacional cuando le soliciten que suspenda cautelarmente la aplicación de una ley eventualmente contraria al Derecho comunitario europeo son en la práctica los mismos.

En el auto de 10 de octubre de 1989 el Presidente del Tribunal de Justicia analiza si concurren los presupuestos del fumus boni iuris y la urgencia. Sobre el fumus, el Presidente es muy escueto pero recuerda el alcance del derecho de establecimiento (apartados 30 y 31 ) y concluye subrayando: «en esta fase del procedimiento de medidas provisionales, no parece que el recurso se halle carente de fundamento» (apartado 33). Sobre la urgencia o periculum in mora, el Presidente también advierte de que los buques que ya estaban faenando no podrían ser explotados en actividades de pesca alternativas y el perjuicio causado sería irreparable en caso de estimación del recurso principal. En fin, respecto de la ponderación de los intereses, el Presidente considera que no se ha demostrado que las medidas provisionales solicitadas puedan amenazar el objetivo que pretende alcanzar la legislación británica consistente garantizar la existencia de un vínculo sustancial entre los buques que faenen a cargo de las cuotas británicas y el sector pesquero británico (apartado 39). En consecuencia, el Presidente obliga al Reino Unido a suspender la aplicación de los requisitos de nacionalidad de la Ley de la marina mercante con respecto a los nacionales de otros Estados miembros y para los buques de pesca que ya faenaban bajo pabellón británico y con licencia de pesca británica.

En la sentencia Factortame I el Tribunal de Justicia le advierte a la Cámara de los Lores: «un órgano jurisdiccional nacional, que esté conociendo de un litigio relativo al Derecho comunitario, debe excluir la aplicación de una norma de Derecho nacional que considere que constituye el único obstáculo que le impide conceder medidas provisionales» (apartado 23).

También en este caso el abogado general Giuseppe Tesauro es consciente de la transcendencia del pronunciamiento del Tribunal de Justicia y subraya desde el principio la especial trascendencia del caso. Asimismo, la respuesta que propone Tesauro será asumida en gran medida por la sentencia del propio Tribunal de Justicia.

Es simbólico comprobar que la cuestión de la suspensión cautelar por los jueces nacionales se hace respecto de una ley adoptada por el Parlamento británico. 
Las consecuencias de la jurisprudencia Factortame I se reflejan en la sentencia Zuckerfabrik Suederdithmarschen donde se plantea no la suspensión de la norma nacional sino de la norma comunitaria. Por eso, el Tribunal de Justicia puntualiza: «la protección provisional garantizada por el Derecho comunitario a los justiciables ante los órganos jurisdiccionales nacionales no puede variar dependiendo de que impugnen la compatibilidad de disposiciones de Derecho nacional con el Derecho comunitario o la validez de actos comunitarios de Derecho derivado, puesto que, en los dos supuestos, la impugnación se basa en el propio Derecho comunitario» (apartado 20).

Por otra parte, el Tribunal de Justicia reconoce en la sentencia Brasserie du pêcheur-Factortame el derecho de indemnización de los particulares para los casos en que hayan sufrido daños como consecuencia de la violación por las autoridades nacionales del Derecho comunitario europeo.

La sentencia Brasserie du pêcheur-Factortame tiene particular importancia por consagrar inequívocamente la responsabilidad del legislador nacional y por fijar ya definitivamente los presupuestos para que surja la responsabilidad por violación del Derecho comunitario europeo. En este sentido, el Tribunal de Justicia fija definitivamente como presupuestos y de un modo más preciso que en Francovich: «los particulares lesionados tienen derecho a una indemnización cuando la norma de Derecho comunitario violada tenga por objeto conferirles derechos, la violación esté suficientemente caracterizada y exista una relación de causalidad directa entre esta violación y el perjuicio sufrido por los particulares» (apartado 74).

El Tribunal de Justicia dedicará sus esfuerzos en la jurisprudencia posterior para precisar lo que debe entenderse por violación suficientemente caracterizada, según la naturaleza de la norma y según la autoridad estatal implicada, así como para detallar el alcance de los principios de equivalencia y de efectividad. Entre Francovich y Brasserie du pêcheur-Factortame se reparten el mérito de que tengamos en estos momentos un Derecho de la Unión Europea más perfecto y eficaz.

\section{Conclusión}

Si atendemos a lo esencial de la jurisprudencia del Tribunal de Justicia, a lo que lo ha hecho grande y respetable, comprobaremos que la clave de su éxito es haber centrado sus preocupaciones en el ciudadano.

Esto fue lo que ocurrió en la primera etapa fundacional en la que, después de una anodina jurisprudencia sobre la compensación financiera de chatarras o la regulación de las ventas de carbón, propia de un órgano técnico administrativo, el Tribunal de Justicia comenzó a resolver problemas de la gente corriente que, a través de sus tribunales más cercanos, incluso 
los más humildes jueces de instancia, le planteaba cuestiones que albergaban insospechados problemas jurídicos de eficacia directa, de primacía sobre las normas nacionales, incluso las de rango legal o constitucional.

Por eso el comentario de los hitos de la jurisprudencia del Tribunal de Justicia desde 1988 no podía tener otro objetivo que comprobar si las cuestiones relativas a problemas cotidianos planteadas por los jueces nacionales al Tribunal de Justicia ponían de manifiesto la virtualidad del Derecho de la Unión.

Siempre hay un antes, por muy modesto que sea, y un después, probablemente mucho más brillante, pero lo importante son los pasos decisivos que ha dado el Tribunal de Justicia y que se pueden identificar con lo que reclamaban Francovich, Bosman, Kadi y Factortame.

De este modo, la insolvencia de las empresas y la manifiesta inoperancia del legislador nacional merecían un correctivo consistente en el derecho a la indemnización de los daños sufridos. Las trabas al desarrollo profesional de los deportistas en un mercado interior europeo debían ser eliminadas aún a costa de alimentar míticas nostalgias de un deporte de aficionados. La inclusión en una lista de terroristas sin respetar los derechos fundamentales no podía sustraerse a un efectivo control judicial ni siquiera cuando la seguridad era apremiante y los avales los presentase el mismo Derecho de las Nacionales Unidas. O, en fin, las restricciones discriminatorias por razón de la nacionalidad de los armadores consagradas en una ley del Parlamento por antonomasia en Europa no podían vulnerar flagrantemente los derechos conferidos por el nuevo ordenamiento europeo sin facultar al juez nacional a suspender provisionalmente su aplicación ni obtener una reparación apropiada por una violación tan suficientemente caracterizada.

Visto en una perspectiva más amplia, quizás las sentencias del Tribunal de Justicia no aporten nuevas construcciones a los principios seculares del Derecho; no obstante, lo que pretenden es que conceptos tan esenciales como responsabilidad, libertad, igualdad o prosperidad tengan un designio inequívocamente europeo.

\section{Jurisprudencia citada}

1. TJCE, sentencia de 16 de diciembre de 1960, Humblet (C-6/60, Rec. p. 1125).

2. TJCE, sentencia de 5 de febrero de 1963 , Van Gend \& Loos (26/62, Rec. p. 1).

3. TJCE, sentencia de 15 de julio de 1964 Flaminio Costa / E.N.E.L. (6/64, Rec. p. 1141).

4. TJCE, sentencia de 25 de mayo de 1971, Gabrielle Defrenne / Estado belga (80/70, Rec. p. 445). 
5. TJCE, sentencia de 12 de diciembre de 1974, Walrave y Koch (36/74, Rec. p. 1405).

6. TJCE, sentencia de 8 de abril de 1976, Gabrielle Defrenne / SABENA (43/75, Rec. p. 455).

7. TJCE, sentencia de 14 de julio de 1976 (Donà, 13/76, Rec. p. 1333).

8. TJCE, sentencia de 9 de marzo de 1978, Simmenthal (106/77, Rec. p. 629).

9. TJCE, sentencia de 15 de junio de 1978, Gabrielle Defrenne / SABENA (149/77, Rec. p. 1365).

10. TJCE, auto de 10 de octubre de 1989, Comisión/Reino Unido (C-246/89 R, Rec. p. 3125)

11. TJCE, sentencia de 19 de junio de 1990, Factortame I (C-213/89, Rec. p. 2433).

12. TJCE, sentencia de 13 de noviembre de 1990, Marleasing (C-106/89, Rec. p. I-4135).

13. TJCE, sentencia de 21 de febrero de 1991, Zuckerfabrik Suederdithmarschen (C-143/88 y C-92/89, Rec. p. I-415).

14. TJCE, sentencia de 25 de julio de 1991, Factortame II (C-221/89, Rec. p. I-3905).

15. TJCE, sentencia de 4 de octubre de 1991, Comisión/Reino Unido (C-246/89, Rec. p. I-4585).

16. TJCE, sentencia de 19 de noviembre de 1991, Francovich y otros (C-6/90 y C-9/90, Rec. p. I-5357).

17. TJCE, sentencia de 24 de noviembre de 1993, Keck y Mithouard (C-267/91 y C-268/91, Rec. p. I-6097).

18. TJCE, sentencia de 14 de febrero de1995, Schumacker (C-279/93, Rec. p. I-225).

19. TJCE, sentencia de 15 de diciembre de 1995, Bosman (C-415/93, Rec. p. I-4921).

20. TJCE, sentencia de 5 de marzo de 1996, Brasserie du Pêcheur y Factortame (C-46/93 y C-48/93, Rec. p. I-1029).

21. TJCE, sentencia de 8 de octubre de 1996, Dillenkofer y otros (C-178/94, C-179/94, C-188/94, C-189/94 y C-190/94, Rec. p. I-4845).

22. TJCE, sentencia de 12 de julio de 2001, Ordine degli Architetti delle province di Milano e Lodi (Teatro alla Scala) (C-399/98, Rec. p. I-5409).

23. TJCE, sentencia de 8 de mayo de 2003, Deutscher Handballbund (C-438/00, Rec. p. I 4135).

24. TJCE, sentencia de 30 de septiembre de 2003, Köbler (C-224/01, Rec. p. I-10239). 
25. TJCE (Gran Sala), sentencia de 12 de abril de 2005, Simutenkov (C-265/03, Rec. p. I-2579).

26. TJCE (Gran Sala), sentencia de 13 de junio de 2006, Traghetti del Mediterraneo (C-173/03, Rec. p. I-5177).

27. TJCE, auto de 25 de julio de 2008, Nihat Kahveci (C-152/08, Rec. p. I-6291).

28. TJCE (Gran Sala), sentencia de 3 de septiembre de 2008, Yassin Abdullah Kadi y Al Barakaat International Foundation / Consejo y Comisión (C-402/05 P y C-415/05 P, Rec. p. I-6351).

29. TJUE (Gran Sala) sentencia de 26 de enero de 2010, Transportes Urbanos y Servicios Generales (C-118/08, Rec. p. I-635).

30. TJUE (Pleno), sentencia de 27 de noviembre de 2012, Pringle (C-370/12, pendiente de publicar en la Recopilación).

31. TJUE (Gran Sala) sentencia de 26 de febrero de 2013, Melloni (C-399/11, pendiente de publicar en la Recopilación).

32. TJUE sentencia de 14 de marzo de 2013, Aziz / Catalunyacaixa (C-415/11, pendiente de publicar en la Recopilación). 